\title{
CHANGES IN CORNEAL TOPOGRAPHY AFTER SMALL INCISION LENTICULAR EXTRACTION FOR MYOPIC PATIENTS
}

\author{
By \\ Omar Maher Ibrahim, Sayed Abbas Sayed, and Mahmoud Mohamed \\ Saleh \\ Ophthalmology Department, Faculty of Medicine, Al-Azhar University, Cairo, Egypt \\ Corresponding author: Omar Maher Ibrahim
}

Mobile: 01003331410, E-mail: omarmaher400@ gmail.com

\begin{abstract}
Background: SMILE does not require the creation of a flap. This reduces the risks associated with flap creation such as dry eye and traumatic flap dislocation.

Objective: To assess corneal curvature changes of anterior and posterior surfaces in terms of corneal power, the radius of curvature, and asphericity following SMILE procedure for myopic patients.

Patients and Methods: Thiswas A prospective comparative study which included 20 eyes of 10 myopic patients. Spherical equivalent (SE) refraction was from -3 to -8 diopters (D) and refractive astigmatism was $<$ -3 D. All patients were treated for myopia and myopic astigmatism using SMILE procedure in AL NOUR EYE HOSPITAL using (500 kHs, Visumax, Carl Zeiss, Meditec, Jena, Germany) starting from January 2018 till June 2019.

Results: A statistically significant decrease in mean keratometric power in the $5 \mathrm{~mm}$ zones of the anterior corneal surface was detected after 1month compared with its pre- SMILE values. The mean posterior keratometry power showed insignificant change. The mean anterior corneal curvature (mean radii of curvature) showed a statistically significant increase after 1-month compared to preoperative values. The mean postoperative posterior curvature showed an insignificant change. Asphericity (Q-value) of the anterior corneal surface changed significantly 1-month postoperatively. Q-value of the posterior corneal surface showed insignificant change. A statistically significant decrease in mean spherical equivalent (SE) was detected after 1month compared with its preoperative value.
\end{abstract}

Conclusion: SMILE is safe; give effective high successful refractive results, good stability and the incidence of intraoperative or postoperative complications remains minimal after one month follow up. SMILE causes significant increase in anterior corneal curvature power, Q-value and significant decrease in anterior keratometry, spherical equivalent and, central corneal thickness.

Keywords: FLEX, SMILE, Central corneal thickness, and pentacam.

\section{INTRODUCTION}

SMILE (small incision lenticule extraction) was described by Sekundo et al. (2011) and became clinically available in 2011. The procedure does not require the creation of a flap. The intrastromal lenticule is taken out through a small 2- to 5-mm incision. This reduces the risks associated with flap creation, such as dry eye, traumatic flap dislocation, and epithelial ingrowth Lin et al (2014).

The present study aimed to assess corneal tomographic changes regarding curvature changes (anterior and posterior) 
in terms of mean radius of curvature, corneal power, and asphericity, as well as to assess corneal thickness (pachymetry) changes following smile procedures for myopic patients.

\section{PATIENTS AND METHODS}

A prospective comparative study included 20 eyes of 10 myopic patients. All patients were treated for myopia and myopic astigmatism using the SMILE procedure in AL NOUR EYE HOSPITAL using (500 kHs, Visumax, Carl Zeiss, Meditec, Jena, Germany) starting from January 2018 till June 2019. The study was approved by the Ethics Board of AlAzhar University. Inclusion criteria included age range 20-40 years old (range 22-38). All myopic patients were stable for at least 1 year. Corrected distance visual acuity (CDVA) was 0.7 OR better, spherical equivalent (SE) refraction was up to-6.5D, myopic astigmatism up to -2 using the SMILE procedure. The minimum corneal thickness was $500 \mu \mathrm{m}$. Exclusion criteria included cases with a history of any previous refractive surgeries or contact lens wearer, previous ocular surgeries, pregnancy or breastfeeding, keratoconus, anterior or posterior segment diseases, and systemic medications or diseases that affect wound healing such as corticosteroid and Rheumatoid arthritis.

Preoperative Examination included uncorrected distance visual acuity (UDVA), best spectacle-corrected visual acuity (BSCVA) using decimal fraction chart, cycloplegic refraction and intraocular pressure (IOP). Corneal tomographic measures were performed using oculus pentacam including corneal curvature changes by measuring mean keratometry power $(\mathrm{Km})$ of anterior and posterior corneal surfaces, mean radii of curvature of anterior and posterior corneal surfaces and asphericity (Q- value) of the anterior and posterior surfaces. Corneal thickness (Pachymetry) was also measured.

Complete ophthalmic examination was done after 1 day, 1 week and 1 month postoperatively, and Pentacam was done 1 month postoperatively.

A written informed consent was obtained from all participants after providing an adequate explanation about the study goals.

In this study, we used oculus pentacam in a room with a standard dim illumination.

The rotating Scheimpflug camera captured 50 images automatically around the optical axis of the eye.

The procedure was performed in several steps. When ready, the patient was brought underneath the femtosecond laser (Visumax, Carl Zeiss, Erlangen, Germany).

The suction ring was applied to the eye prior to the patient interface being moved into position, the laser first created the posterior lenticule surface (from peripheral to central) followed by a transition zone at the edge of the refractive zone which represented the refractive correction. Vertical edge incisions was around the perimeter of the refractive zone (lenticule). The anterior lenticule surface was then ablated (from centre to periphery). Finally, the peripheral corneal incisions were created to allow for the lenticular extraction. 
The following femtosecond laser parameters were used: $100 \mu \mathrm{m}$ anterior stromal layer (ASL) thicknesses, $7.5 \mathrm{~mm}$ anterior-plane cut diameter, $6.5 \mathrm{~mm}$ optical zone of lenticule, $160 \mathrm{~nJ}$ of energy with lenticule side-cut angles at $135^{\circ}$. A $2.1 \mathrm{~mm}$ entrance wound was created centered between 9 and 12 o'clock in all cases.

The spot distance and tracking spacing were $4.5 / 4.5 \mu \mathrm{m}$ for the posterior lenticule plane, $2.5 / 2.5 \mu \mathrm{m}$ for the lenticule sidecut, $4.5 / 4.5 \mu \mathrm{m}$ for the anterior lenticule plane and $2.5 / 2.5 \mu \mathrm{m}$ for the entrance wound side-cut.

The procedure took approximately 30 seconds in most cases.

Chansue ReLEx Dissector (CRD) was then used to separate the posterior surface of the ASL from the anterior surface of the lenticule, then to release the lenticule from its bed. The lenticule was then grasped and extracted with a pair of nontoothed serrated micron forceps through the small incision. Vigamox and Tobradex were prescribed one drop in each eye three times per day for one week following surgery. Fluorometholone (FML, Allergan, California, USA) was then prescribed on a titrating basis for a further two weeks.

\section{Statistical Analysis:}

Data were collected, tabulated, statistically analyzed using an IBM personal computer with Statistical Package for the Social Science (SPSS) version 22 (SPSS, Inc, Chicago, Illinois, USA).

Descriptive statistics: were presented in the form of mean standard deviation (SD), and range.

Analytical statistics: was used to find out the possible association between studied factors and the targeted disease. The used tests of significance included:

Paired t-test: for comparison between two related groups having quantitative variables.

Pearson correlation coefficient (r): to measure the association between two quantitative variables. $\mathrm{P}$ value of $<0.05$ was considered statistically significant.

\section{RESULTS}

The study included 20 eyes of 10 myopic patients (5 females $50 \%$ ) and (5 male $50 \%$ ) underwent a smile procedure. Tomographic assessment of the cornea was done and recorded preoperatively and1month postoperatively. The age of patients ranged from 20 to 40 years old, the mean age was $29.7 \pm 5.73$ SD. All patients were treated for myopia SE up to $-6.5 \mathrm{D}$ with and myopic astigmatism up to $-2 \mathrm{D}$ using the SMILE procedure. The mean age of the study group was 29.7 \pm 5.73 SD (range 22-38) (Table 1). 
OMAR MAHER IBRAHIM et al.,

Table (1): Some descriptive Statistic values of the studied group

\begin{tabular}{|c|c|c|c|c|c|c|}
\hline Variables & No. & Minimum & Maximum & Mean & $\begin{array}{c}\text { Std. } \\
\text { Deviation(SD) }\end{array}$ & P-value \\
\hline $\begin{array}{c}\text { Pre- } \\
\text { BCVA }\end{array}$ & 20 & 0.80 & 1.00 & 0.97 & 0.06 & $<0.001$ \\
\hline $\begin{array}{c}\text { Post- } \\
\text { BCVA }\end{array}$ & 20 & 0.80 & 1.00 & 0.94 & 0.08 & $<0.001$ \\
\hline $\begin{array}{c}\text { Pre- Sph. } \\
\text { Equiv./D }\end{array}$ & 20 & -2.50 & -6.50 & -4.43 & 1.21 & $<0.001$ \\
\hline $\begin{array}{c}\text { Post-Sph. } \\
\text { Equiv/D }\end{array}$ & 20 & -0.75 & 0.25 & -0.28 & 0.22 & $<0.001$ \\
\hline Pre-IOP & 20 & 10.70 & 15.60 & 12.74 & 1.45 & $<0.001$ \\
\hline $\begin{array}{c}\text { Post- } \\
\text { IOP }\end{array}$ & 20 & 8.30 & 13.20 & 11.12 & 1.41 & $<0.001$ \\
\hline
\end{tabular}

Pre $=$ preoperative Post $=$ postoperative

The anterior and posterior surfaces of the cornea were examined for curvature changes in terms of mean keratometry power $(\mathrm{Km}=\mathrm{K}$-avg), mean radii of curvature (Rm), asphericity (Q-value) and pachymetry (Table 2).

Table (2): Descriptive topographic preoperative data of the study group

\begin{tabular}{|c|c|c|c|c|c|c|c|c|c|c|}
\hline \multirow{2}{*}{ Variables } & \multirow{2}{*}{ No. } & \multicolumn{2}{|c|}{ Minimum } & \multicolumn{2}{|c|}{ Maximum } & \multicolumn{2}{|c|}{ Mean } & \multicolumn{2}{c|}{$\begin{array}{c}\text { Std. } \\
\text { Deviation(SD) }\end{array}$} & $\begin{array}{c}\text { P- } \\
\text { value }\end{array}$ \\
\cline { 3 - 11 } & & Pre & Post & Pre & Post & Pre & Post & Pre & Post & \\
\hline $\begin{array}{c}\text { Mean anterior } \\
\text { Curvature (Rm) }\end{array}$ & 20 & 7.42 & 8.05 & 8.07 & 8.85 & 7.79 & 8.43 & 0.18 & 0.26 & $<0.05$ \\
\hline $\begin{array}{c}\text { Mean. posterior } \\
\text { Curvature (Rm) }\end{array}$ & 20 & 6.08 & 6.02 & 6.66 & 6.63 & 6.39 & 6.39 & 0.18 & 0.19 & $>0.05$ \\
\hline $\begin{array}{c}\text { Anterior } \\
\text { Asphericity }\end{array}$ & 20 & -0.56 & -0.45 & -0.14 & -0.24 & -0.37 & -0.36 & 0.113 & 0.629 & $<0.05$ \\
\hline $\begin{array}{c}\text { Posterior } \\
\text { Asphericity }\end{array}$ & 20 & -0.44 & -0.03 & -0.22 & 0.87 & -0.36 & 0.36 & 0.697 & 0.239 & $>0.05$ \\
\hline $\begin{array}{c}\text { Mean anterior } \\
\text { Keratometry/ D } \\
\text { (Km = K-avg) }\end{array}$ & 20 & 41.80 & -6.2 & 45.55 & -6.8 & 43.450 & -6.43 & 0.980 & 0.18 & $<0.05$ \\
\hline $\begin{array}{c}\text { Mean posterior } \\
\text { Keratometry/ D } \\
\text { (Km = K-avg) }\end{array}$ & 20 & -6.2 & 38.20 & -6.7 & 41.95 & -6.40 & 40.17 & 0.168 & 1.144 & $>0.05$ \\
\hline $\begin{array}{c}\text { Corneal } \\
\text { Thickness } \\
\text { (pachymetry) }\end{array}$ & 20 & 493.00 & 398.00 & 586.00 & 531.00 & 545.65 & 471.90 & 32.74 & 39.74 & $<0.05$ \\
\hline
\end{tabular}




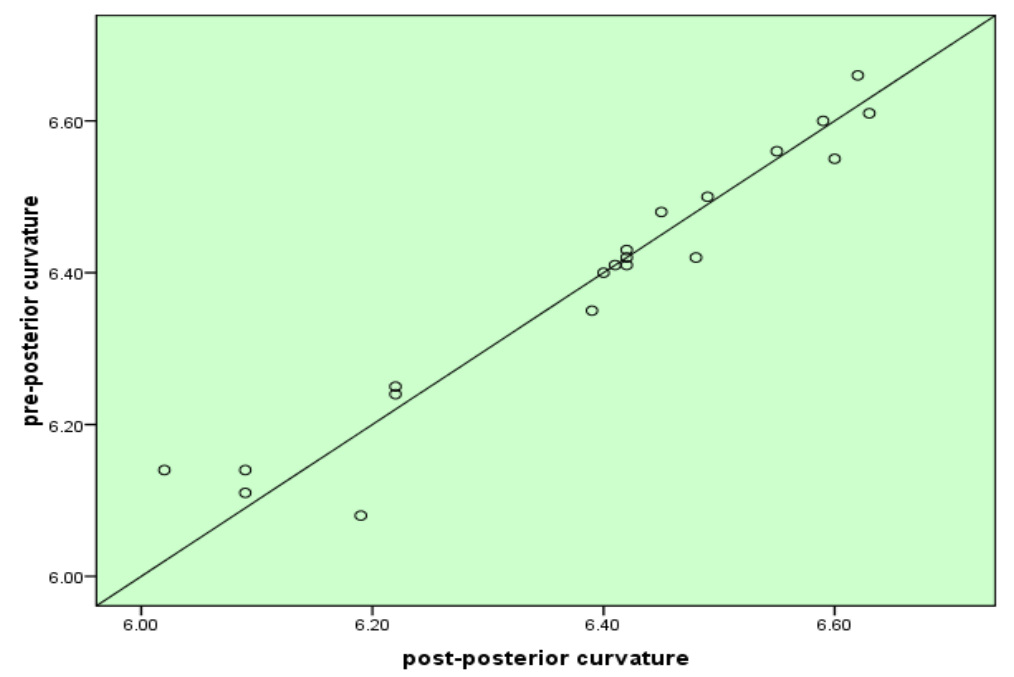

Figure (1): Correlation between preoperative and postoperative mean radii of posterior corneal curvature $(\mathrm{Rm})(\mathrm{P}$ - value $<0.05)$

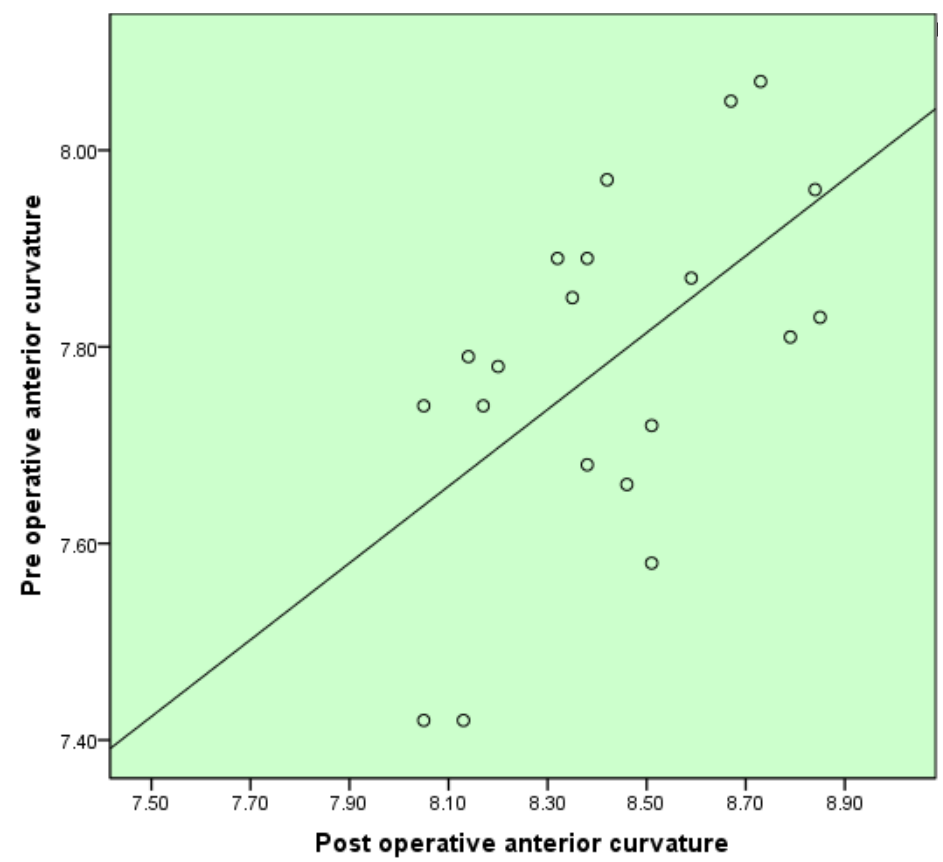

Figure (2): Correlation between preoperative and postoperative mean radii of anterior corneal curvature $(\mathbf{R m})(\mathrm{P}$ - value $<\mathbf{0 . 0 5})$

There positive correlation between Preoperative and postoperative Posterior corneal asphericity (Table 3).

Table (3): Correlation between Preoperative Posterior Asphericity \& 1-month Postoperative Posterior Asphericity

\begin{tabular}{|c|c|c|c|}
\hline Variable & N & Correlation (r) & Sig. (p-value) \\
\hline $\begin{array}{c}\text { Pre-Posterior-Asphericity \& Post- } \\
\text { Posterior- Asphericity }\end{array}$ & 20 & 0.941 & $<0.001$ \\
\hline
\end{tabular}




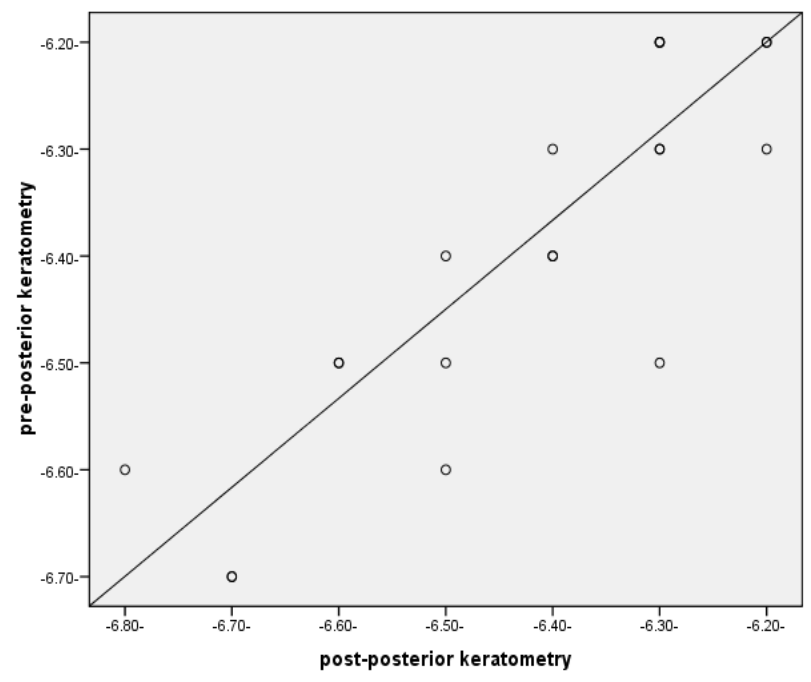

Figure (3): Correlation between preoperative and postoperative mean curvature power of the posterior corneal surface $(\mathrm{Km}=\mathrm{K}$-avg) $(\mathrm{P}$ - value $<0.05)$.

One month postoperatively, a statistically significant decrease in mean keratometry power at the anterior corneal surface $(\mathrm{P}<0.05)$ was detected. A significant increase of postoperative anterior corneal curvature (mean radii of curvature) after 1 - month $(\mathrm{P}<0.05)$ was seen. Asphericity (Q-value) of the anterior surface changed significantly $(\mathrm{P}<0.05)$ $5 \mathrm{~mm}$ zone, in which it changed from

\section{DISCUSSION}

The current study aimed to assess corneal curvature changes following small incision lenticular extraction (SMILE) in myopic patients. Pentacam is used to evaluate corneal tomography changes.

Pentacam is used to evaluate some of the corneal topography in the present study. In the current study, the mean age of the studied group was $29.7 \pm 5.73$ years. Their ages ranged from 22 to 38 years, and $50 \%$ of the studied group were males and $50 \%$ were females, and $50 \%$ of studied groups had right eye affected and $50 \%$ of them had affected the left eye. prolate (mean -0.37) to oblate (mean 0.36).

No statistically significant changes were detected $(\mathrm{P}>0.05)$ in keratometry, mean radii of curvature and asphericity of the posterior corneal surface.

Central corneal thickness showed a statistically significant decrease in postoperatively $(\mathrm{P}<0.05)$.

In the present study, there was a significant difference between pre and postoperative mean spherical equivalent. The spherical equivalent preoperatively was $-4.43 \pm 1.21 \mathrm{D}$ and when seen 1 month postoperatively was $0.28 \pm 0.22 \mathrm{D}$. This result was similar to the study done by Sekundo et al. (2011) who reported a significant decrease of mean spherical equivalent postoperatively after SMILE procedure, where the spherical equivalent was $-4.75 \pm 1.56$ preoperatively and $-0.01 \pm 0.496$ months postoperatively.

Hjortdal et al. (2012) reported a significant decrease of mean spherical equivalent postoperatively after a smile 
procedure where preoperative value was-7.19 $\pm 1.30 \mathrm{D}$ and 3 months postoperatively was $-0.25 \pm 0.44 \mathrm{D}$.

On the other hand, higher results of a significant decrease of mean spherical equivalent were obtained by Han et al. (2016) who reported a decrease of spherical equivalent from $-6.30 \pm 1.47 \mathrm{D}$ preoperatively to $-0.09 \pm 0.39$ after 4 years of follow up after SMILE procedure. Similar results were reported by Zhu et al. (2017) who found a significant decrease of spherical equivalent from-7.91 $\pm 1.08 \mathrm{D}$ preoperatively to $0.327 \pm 0.314 \mathrm{D}$ postoperatively following SMILE procedure.

In the current study, a significant difference was seen between pre and postoperative mean anterior corneal curvature, despite there was an insignificant difference between pre and postoperative posterior corneal curvature, there was a significant correlation between them.

Similar results were obtained by Abdelhalim (2019) who found significant changes in the mean radii of curvature of anterior corneal surface, but no significant change of the posterior corneal curvature.

In the present study, there was a significant difference between pre and postoperative mean anterior corneal asphericity (Q-value). There was a tendency for the $\mathrm{Q}$ value to become more positive after myopic ablation in which it changed from prolate to oblate. However, there was no significant difference between pre and postoperative posterior corneal asphericity. The results of the present study were similar to those obtained by Abdelhalim (2019) after 6 months follow up. The results of current study agreed with that obtained by Ganesh et al. (2015) for asphericity of anterior corneal surface, but disagreed with their results obtained for asphericity of posterior corneal surface where they found a statistically significant difference between preoperative and postoperative anterior and posterior corneal asphericity in moderate and high myopia but not in low myopia after 3 months follow up period. They also stated that there is an increase in prolate asphericity of posterior curvature due to most of cases high myopic.

In the current study, there was a significant difference between mean pre and postoperative anterior curvature power where there was a decrease of anterior curvature power, i.e flattening, and also there was a significant correlation between them. The present study showed an insignificant difference between preoperative and postoperative mean curvature power of posterior corneal surface, but there was a positive correlation between them. These results were similar to the results obtained by Vestergaard et al. (2014) after 6 months postoperatively, by Abdelhalim (2019) after 12 months follow up and by $W u$ et al. (2020) after 6 months postoperatively. The results of the present study as regard to posterior corneal curvature power disagreed with that of the Ganesh et al. (2015) who found a significant statistical difference between preoperative and postoperative power and increase negative central power of posterior corneal curvature together with increase prolate asphericity of posterior curvature suggest increase prolatness of posterior corneal surface due to high myopic cases. 
In the present study, there was a significant difference between mean pre and postoperative corneal thickness (decrease in corneal thickness). These results agreed with those obtained by Vestergaard et al. (2014) No complications seen intra or postoperatively.

These results showed that the SMILE was safe, and gave effective high successful refractive results and good stability.

The current study showed corneal curvature changes significantly in the anterior corneal surface, but not in the posterior corneal surface. This agreed with the results obtained by Gyldenkerne et al. (2015).

\section{Limitations:}

Short period of follow up period, longer-term follow-up visits would have been desirable. More number of cases are required for better assessment of changes of posterior corneal curvature. Only patients with myopia with low astigmatism were included in the present study. Calculating the average curvature in different diameters eliminates the possibility of assessing any potential regional, asymmetric differences in corneal curvature.

\section{CONCLUSION}

SMILE is safe, gave effective high successful refractive results, good stability and the incidence of intraoperative or postoperative complications remains minimal after one month follow up. SMILE causes significant increase in anterior corneal curvature power, Q-value and significant decrease in anterior keratometry, spherical equivalent and, Central corneal thickness.

\section{REFERENCES}

1. Abdelhalim N. (2019): Corneal Topographic and Biomechanical Changes after Small Incision Lenticule Extraction (SMILE) in Myopic Eyes. The Egyptian Journal of Hospital Medicine, 74 (3): 558563.

2. Ganesh $S$; Patel $U$ and Brar $S$ (2015): Posterior corneal curvature changes following Refractive Small Incision Lenticule Extraction. Clinical Ophthalmology, 9:1359-1364.

3. Gyldenkerne A; Ivarsen $A$ and Hjortdal J. (2015): Comparison of Corneal Shape Changes and Aberrations Induced By FS-LASIK and SMILE for Myopia. J Refract Surg., 31(4):223-229.

4. Han T; Zheng K; Chen Y; Gao Y; He L. and Zhou X. (2016): Fouryear observation of predictability and stability of small incision lenticule extraction. BMC Ophthalmology, 16(1): 149.

5. Hjortdal, J. Ø., Vestergaard, A. H., Ivarsen, A., Ragunathan, S., and Asp, S. (2012): Predictors for the outcome of small-incision lenticule extraction for myopia. Journal of Refractive Surgery, 28(12): 865-871.

6. Lin F, Xu Y and Yang Y (2014): Comparison of the visual results after SMILE and femtosecond laserassisted LASIK for myopia. J Refract Surg, 30 (4):248-254. 
7. Sekundo W, Kunert KS and Blum $M$ (2011): Small incision corneal refractive surgery using the small incision lenticule extraction (SMILE) procedure for the correction of myopia and myopic astigmatism: results of a 6 month prospective study. British Journal of Ophthalmology, 1; 95(3):335-9.

8. Vestergaard, Anders, H., Grauslund, J., Ivarsen, A. R., and Hjortdal, J. Ø. (2014): Efficacy, safety, predictability, contrast sensitivity, and aberrations after femtosecond laser lenticule extraction. Journal of Cataract \& Refractive Surgery, 40(3): 403-411.

9. Wu, D., Liu, C., Li, B., Wang, D., and Fang, X. (2020): Influence of Cap Thickness on Corneal Curvature and Corneal Biomechanics after SMILE: A Prospective, Contralateral Eye Study. Journal of Refractive Surgery, 36(2): 82-88.

10. Zhu X, Zou L, Yu M, Qiu C, Chen $M$ and Dai $J$ (2017): Comparison of postoperative visual quality after SMILE and LASEK for high myopia: A 1-year outcome. PLoS ONE, 12(8): e0182251. 


\section{التغيرات التي تحدث في تضاريس القرنية للعين بعد عمليات

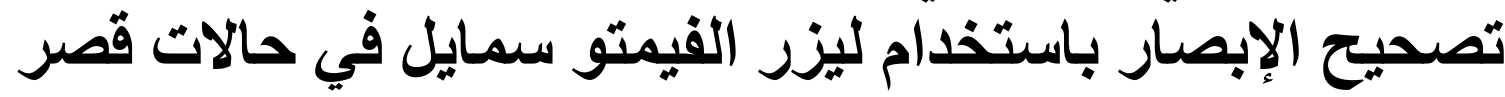 النظر}

عمر ماهر ابراهيم عوض، سيد عباس سيد محفوظ، محمود محمد صالح

قسم طب وجراحة العيون بكلية الطب، جامعة الأزهر

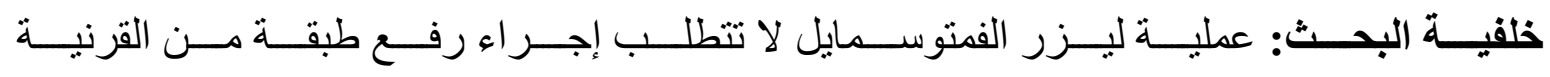

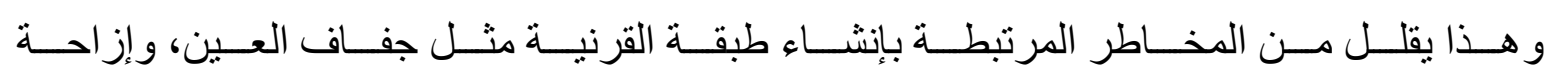
هذه الطبقة.

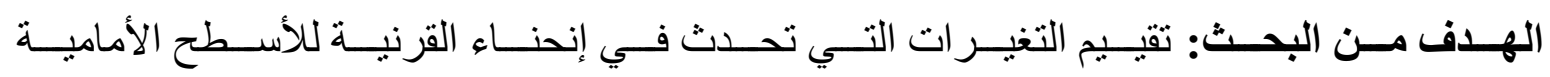

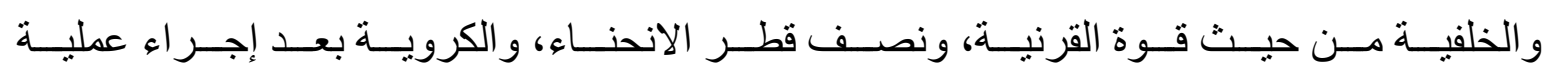
ليزر الفمتوسمايل لمرضى قصر النظر.

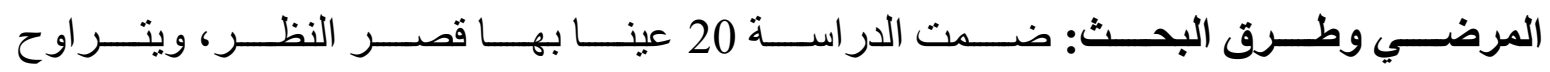

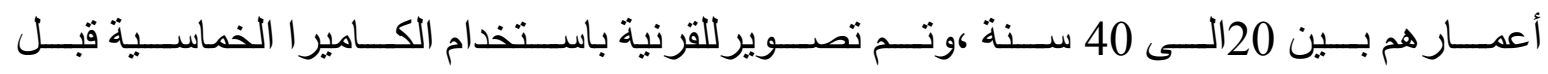

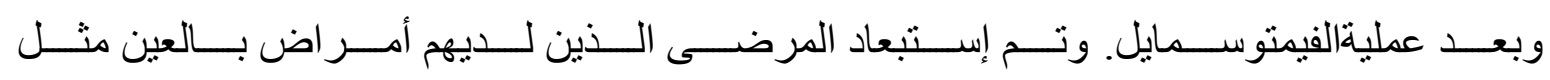

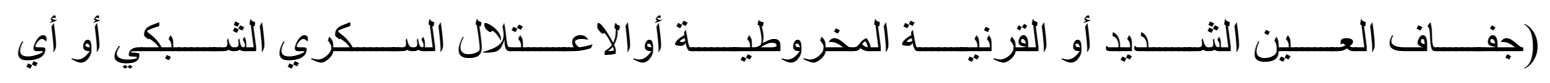

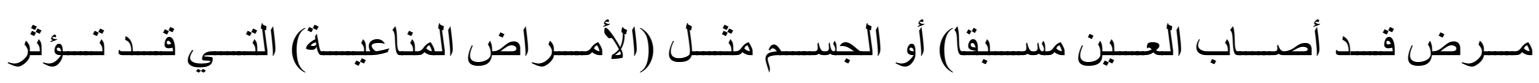

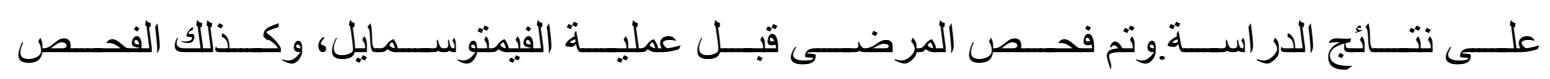

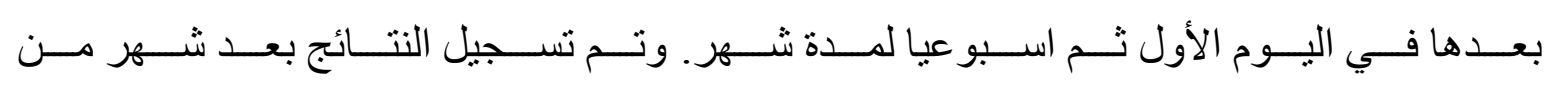

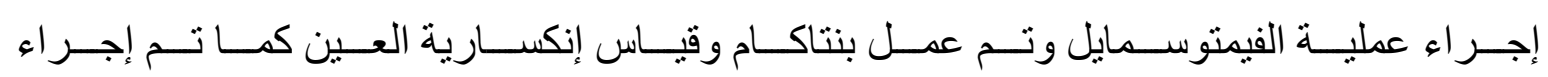

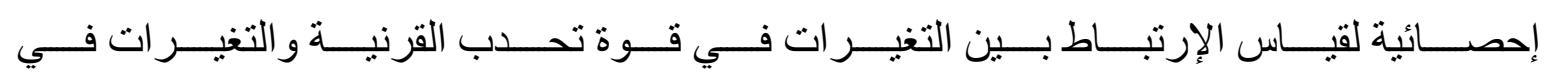
إنكسارية العين وكذلك التغيرات التي قد تحدث في طبو غر افيا القرنية.

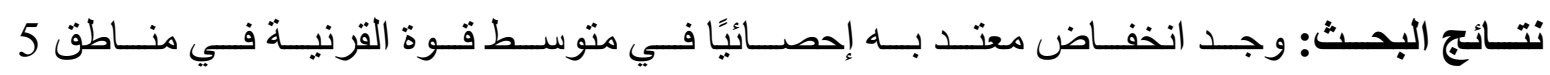

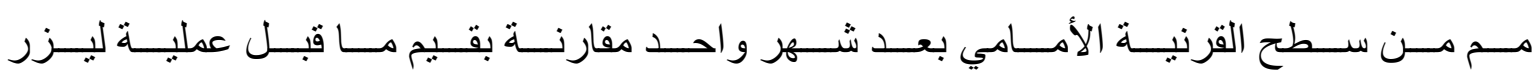

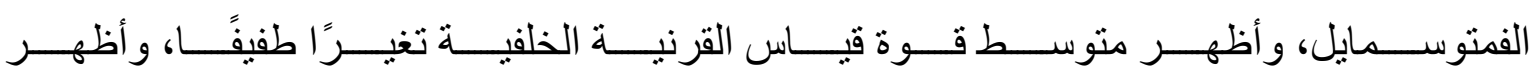

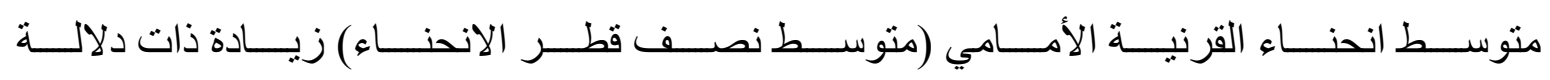

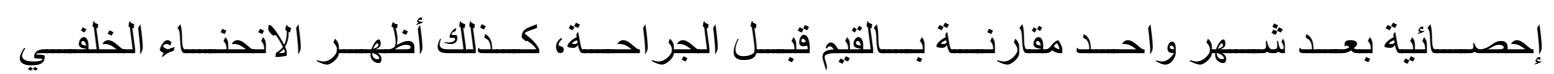




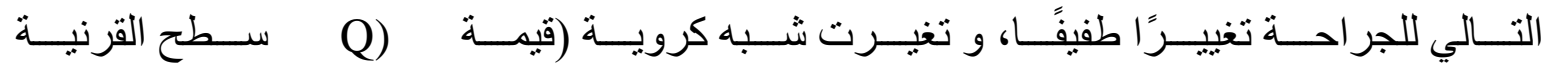

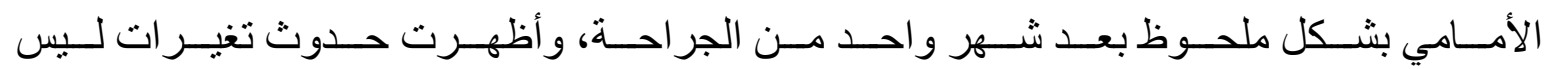

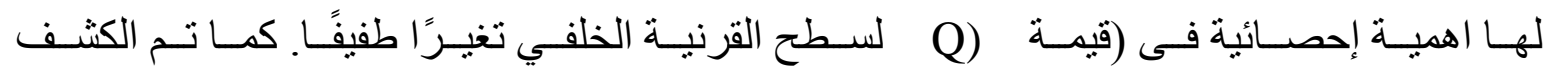

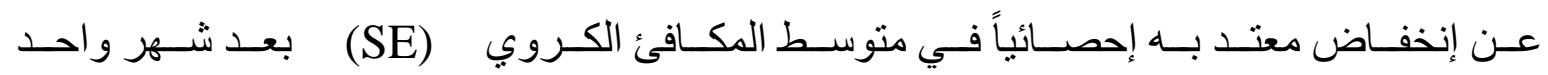
مقارنةً بقيمته قبل الجر احة.

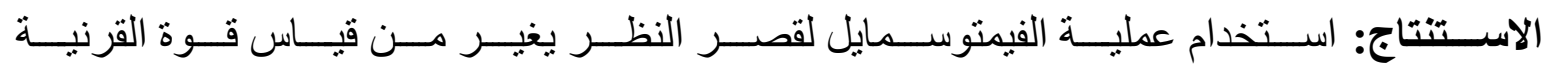

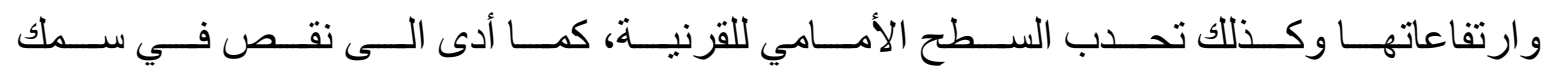

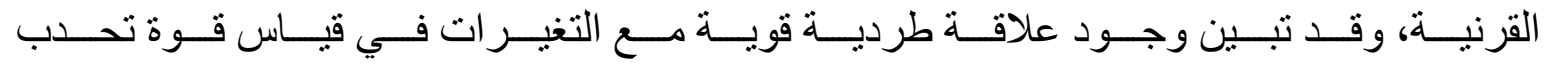

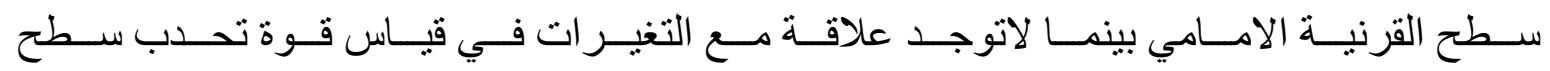

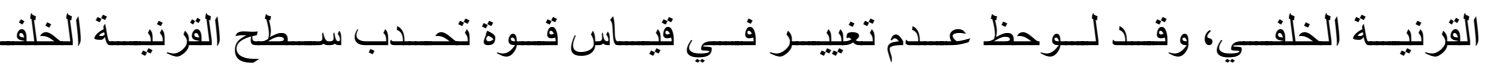
وارتفاعات السطح الخلفي للقرنية. 